\title{
Long-term evolution of squamous-cell cancer in Plummer-Vinson syndrome
}

\author{
Ulaş Aday ${ }^{1}$, Ebubekir Gündeş ${ }^{1}$, Durmuş Ali Çetin ${ }^{1}$, Hüseyin Çiyiltepe ${ }^{1}$, Kayhan Başak ${ }^{2}$, Mustafa Duman ${ }^{1}$ \\ ${ }^{1}$ Gastroenterological Surgery Department, Kartal Koşuyolu High Speciality and Training Hospital, Istanbul, Turkey \\ 2Department of Pathology, Kartal Lütfi Kırdar Education and Resource Hospital, Istanbul, Turkey
}

Gastroenterology Rev 2017; 12 (3): 226-228

DOI: https://doi.org/10.5114/pg.2017.70477

\begin{abstract}
Address for correspondence: Ebubekir Gündeş MD, Gastroenterological Surgery Department, Kartal Koşuyolu High Speciality and Training Hospital, Denizer cad. No: 22, 34000 Istanbul, Turkey, phone: +90 5058606740, e-mail: ebubekir82@hotmail.com
\end{abstract}

Plummer-Vinson syndrome (PVS, Paterson-Kelly) is a clinical condition that is frequently seen in middle-aged women, and is characterised by iron deficiency anaemia, proximal oesophageal web, and dysphagia [1].

Today the progress seen in the amount and variety of foods as well as the more frequent iron replacement practices for women has decreased the prevalence of PVS. It has been stated that there was an increase in the prevalence of cancer in the upper digestive system in patients with PVS [2, 3]. Endoscopic follow-up is recommended because there is an increase in the risk of cancer development in the oral cavity, pharynx, squamous-cell cancer (SCC) of the oesophagus, and gastric adenocarcinoma in long-term follow-ups [3, 4]. The cause of the dysphagia, which was seen 6 years later in our 38-year-old male patient, who had received endoscopic treatment of the oesophageal web and started on iron replacement because of PVS, was advanced-stage local oesophageal SCC.

The 38-year-old male patient had presented to our outpatient clinic 9 years earlier because of dysphagia, fatigue, and weight loss. His evaluation had not revealed any history of chronic illness, smoking, or alcohol consumption. According to his laboratory results his haemoglobin level was $10.5 \mathrm{~g} / \mathrm{dl}$ (normal range: $12.2-18.1$ ), haematocrit level was $35.0 \%$ (normal range: 37.7-53.7), iron level was $12 \mu \mathrm{g} / \mathrm{dl}$ (normal range: 25-156), and mean corpuscular volume (MCV) $64.5 \mathrm{fl}$, which were in line with iron deficiency anaemia. The peripheral blood smear conducted within the scope of the initial evaluation for anaemia showed an outlook concordant with iron deficiency anaemia (Figure 1, upper left corner). The barium swallow performed for dysphagia demonstrated narrowness in the proximal oesophagus (Figure 2). Endoscopic evaluation revealed a web causing narrowness in the proximal (Figure 3), and it was dilated by bougie. While the other parts of the oesophagus and stomach were normal, duodenal bulbus was oedematous, and a biopsy was performed. Duodenal biopsy revealed signs of chronic inflammation. The colonoscopic evaluation for anaemia showed no pathological signs. The patient was diagnosed with PVS, started on oral iron preparation, and taken into the follow-up program.

The patient's third-month follow-up showed that his dysphagia had regressed. His laboratory results at this stage were: haemoglobin $14.8 \mathrm{~g} / \mathrm{dl}$, haematocrit 43.2\%, mean corpuscular volume (MCV) $81.6 \mathrm{fl}$, and iron level $104 \mu \mathrm{g} / \mathrm{dl}$. His endoscopic control revealed regression in the narrowness of the previous web of the proximal oesophagus. His iron replacement continued and he was taken into endoscopic follow-up program. The patient, however, did not continue with his follow-up program and presented to our outpatient clinic again because of dysphagia, which developed 6 years after he was first diagnosed, and retrosternal pain. It was seen that the patient's laboratory parameters were within normal ranges. The endoscopic evaluation showed ulcerated lesions in the distal oesophagus, and biopsy samples were collected. Pathological evaluation reported SCC (Figure 1). The radiological evaluation performed for staging revealed $\mathrm{T} 3 \mathrm{~N}+$. The patient was operated following neo-adjuvant chemo-radiotherapy and Ivor-Lewis oesophagostomy was performed. The pathological staging was T3, NO (0/22), MO, and stage IIA according to American Joint Committee on Cancer (AJCC) TNM Staging Classification for SCC of the oesophagus (seventh edition 2010). Repeated balloon dilatations were performed because of anastomotic narrowness in the post-operative period. The patient has been followed-up for 3 years now following oesophagostomy, without any recurrences. 


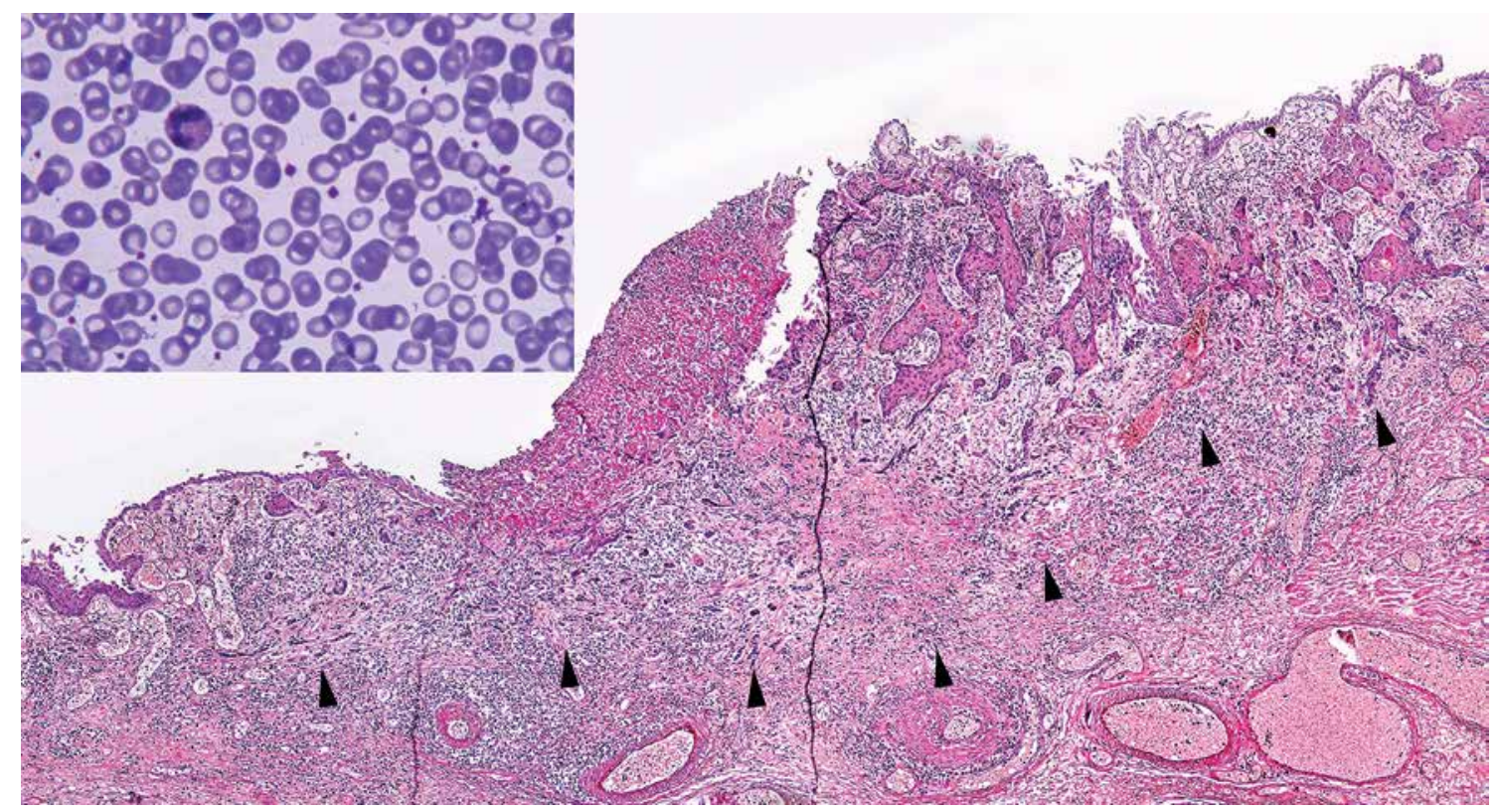

Figure 1. Image of peripheral blood smear on the upper left corner (original magnification 1000x, Giemza), image of invasive tumour cells of SCC on the other area (between arrow heads, original magnification $40 \times, H+E$ )

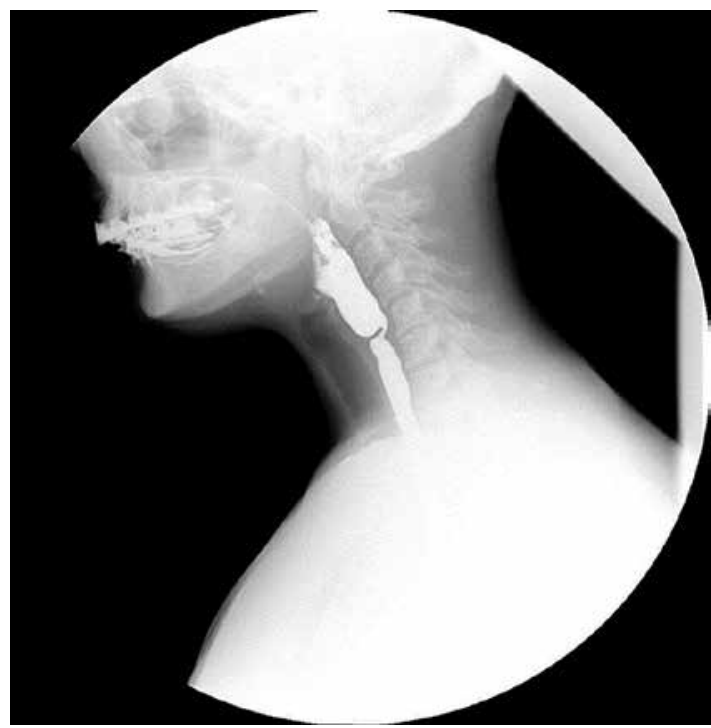

Figure 2. Barium swallow showing oesophageal web

Plummer-Vinson syndrome, which is also known as Paterson-Kelly syndrome, is a clinical situation frequently seen in middle-aged women, which is characterised by the triad of iron deficiency anaemia, dysphagia, and proximal oesophageal web $[3,5]$. Although its aetiology is not clear yet, iron deficiency is the main reason for this condition. It has also been suggested that genetic, environmental, and autoimmune causes could play a role in this condition as well [6]. While many patients are asymptomatic, those who are symptomatic are seen

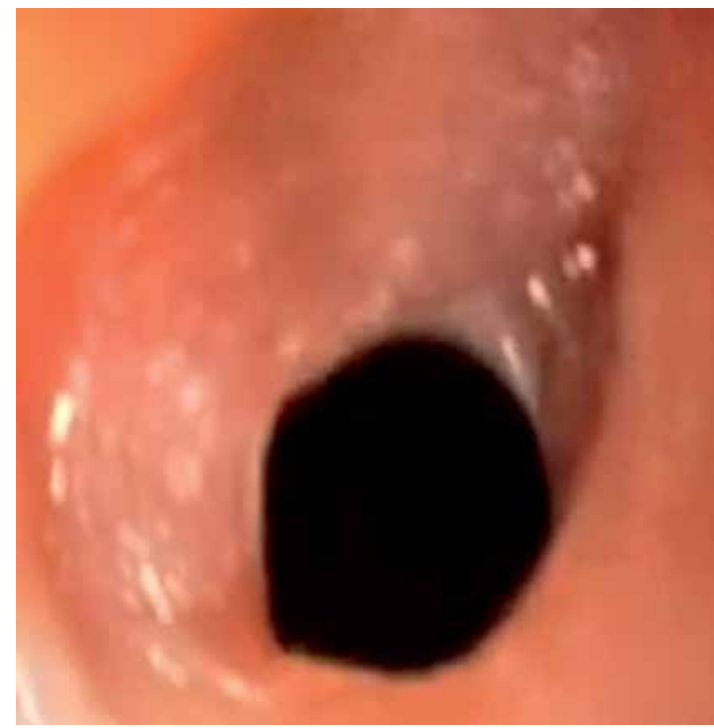

Figure 3. Endoscopic view of oesophageal web

to have dysphagia related to post-cricoid web presence, prostration, pallor, tachycardia, and fatigue developing secondarily to anaemia related to iron deficiency. It is a benign disease, which is treated with iron replacement and endoscopic dilatation for dysphagia [3].

Malignities of the upper digestive system and autoimmune diseases may accompany PVS, and the addition of a malignity to the condition negatively affects clinical progress $[6,7]$. Cancer development has been explained by mucosal degeneration through a decrease in iron-de- 
pendent enzymes, formation of atrophic changes, defects in repair mechanisms, and changes seen in cellular kinetics $[8,9]$. It has been reported that malignity at $3-16 \%$ was seen in the upper digestive systems of patients with PVS, and therefore it has been suggested that yearly endoscopic controls should be performed for such patients $[1,3,7]$. Bakari et al. reported in their study covering 135 PVS patients that 7 (5.2\%) cases had oesophageal SCC [10]. The authors also stated that 2 patients were seen to have cancer in the follow-ups and 5 patients already had cancer at the time of diagnosis. In a study by Chisholm, covering a total of 240 PVS patients, 72 being the author's own series, the long-term follow-up results of these patients revealed that 23 patients developed malignities of the upper digestive system and only 5 (2\%) of these patients had oesophageal cancer [11]. Since not all patients have malignity development, and despite genetic analysis studies for the prediction of cancer development not being covered by routine practices, there are studies on the subject as well $[12,13]$. Badawy et al. suggested in their study that cytogenetic analysis should be performed for PVS patients as a polymorphic marker called CFS1-R, which was detected on the fifth chromosome, was seen in all the cases with post-cricoid cancer [12].

Consequently, cancer development in the upper digestive system in PVS is more frequent than in the normal population. Cancer development is not seen in all the patients, but the addition of a malignity to the condition negatively affects prognosis. It would be rational to specify patients with a high risk through genetic analysis and to take such patients into close follow-up programs.

\section{Conflict of interest}

The authors declare no conflict of interest.

\section{References}

1. Sugiura Y, Nakagawa M, Hashizume T, et al. Iron supplementation improved dysphagia related to Plummer-Vinson syndrome. Keio J Med 2015; 64: 48-50.

2. Hoffman RM, Jaffe PE. Plummer-Vinson syndrome. A case report and literature review. Arch Intern Med 1995; 155: 2008-11.

3. Novacek G. Plummer-Vinson syndrome. Orphanet J Rare Dis 2006; 1: 36.

4. Kim KH, Kim MC, Jung GJ. Gastric cancer occurring in a patient with Plummer-Vinson syndrome: a case report. World J Gastroenterol 2005; 11: 7048-50.

5. Goel A, Lakshmi CP, Bakshi SS, et al. Single-center prospective study of Plummer-Vinson syndrome. Dis Esophagus 2015; 29: 837-41.

6. Fall F, Gning SB, Ndiaye AR, et al. The Plummer-Vinson syndrome: a retrospective study of 50 cases. J Afr Hepatol Gastroenterol 2011; 5: 259-63.
7. Mouna S, Kabbaj N, Raissouni F, et al. Safety and effectiveness of endoscopic Savary-Gillaard Bougies dilation in Moroccan Plummer-Vinson syndrome patients. ISRN Endosc 2013; 2013: 137895.

8. Samad A, Mohan N, Balaji RV, et al. Oral manifestations of Plummer-Vinson syndrome: a classic report with literature review. J Int Oral Health 2015; 7: 68-1.

9. Dinler G, Tander B, Kalaycı AG, Rızalar R. Plummer-Vinson syndrome in a15 year-old boy. Turk J Pediatr 2009; 51: 384-86.

10. Bakari G, Benelbarhdadi I, Bahiije L, Essaid AE. Endoscopic treatment of 135 cases of Plummer-Vinson web: a pilot experience. Gastrointest Endosc 2014; 80: 738-41.

11. Chisholm M. The association between webs, iron and post-cricoid carcinoma. Postgrad Med J 1974; 50: 215-19.

12. Badawy BS, Ahmad MA, Sayed RH, Habib TN. Role of microsatellites instability in carcinogenesis of postcricoid carcinoma on top of plummer-vinson syndrome. Indian J Otolaryngol Head Neck Surg 2010; 62: 417-20.

13. Abou-Elhamd KE, Habib TN, Moussa AE, Badawy BS. The role of genetic susceptibility in head and neck squamous cell carcinoma. Eur Arch Otorhinolaryngol 2008; 265: 217-22.

Received: 9.08.2016

Accepted: 29.10 .2016 